\title{
Diagnostic Strategies in Young Patients with Ischemic Stroke in Canada
}

\author{
Michael T.Y. Chan, Zurab G. Nadareishvili, John W. Norris for the Canadian \\ Stroke Consortium
}

\begin{abstract}
Background: A preliminary national survey of ischemic stroke in the young (15-45 years) undertaken by the Canadian Stroke Consortium indicated that in $44 \%$ of 356 patients, no cause was found. Objective: To determine the reason for this high incidence of diagnostic uncertainty in young patients with ischemic stroke. Methods: Neurologists in the ten Canadian stroke centers completed a detailed questionnaire for patients aged 15-45 years admitted to hospital between January 1993 and December 1997 . Using a stepwise diagnostic algorithm incorporating clinical, neuroimaging, neurovascular and laboratory data, we divided patients into three groups: (1) those with established cause for the ischemic stroke, (2) those who remained unexplained despite adequate investigation, (3) those who remained unexplained but were, in our opinion, under-investigated. Results: In 197 patients (56\%), an identified cause was established including cardioembolic sources (14\%), extracranial arterial dissection (13\%), lacunar infarcts (8\%) atherosclerosis $(6 \%)$. A miscellaneous group of $15 \%$, included cerebral venous thrombosis, coagulopathies, vasculitis and others. In 159 patients (44\%) with no apparent cause for their stroke, we considered only $81(23 \%)$ adequately investigated, and $78(21 \%)$ inadequately investigated. Conclusion: About one in five young patients was inadequately investigated by a stroke-oriented group of neurologists. The major problem appears to be restriction of investigations to neuroimaging alone (usually computerized cerebral tomography), without further tests such as cerebral angiography and cardiac imaging.
\end{abstract}

RÉSUMÉ:Stratégies diagnostiques chez des patients jeunes qui ont subi un accident vasculaire cérébral ischémique au Canada. Introduction: Une enquête nationale préliminaire sur l'accident vasculaire cérébral (AVC) ischémique chez les jeunes (15 à 45 ans) sous l'égide du Canadian Stroke Consortium indique qu'aucune cause n'a été mise en évidence chez $44 \%$ des 356 patients étudiés. Objectif: Déterminer la raison de ce haut taux d'incertitude diagnostique chez des patients jeunes qui ont subi un AVC ischémique. Méthodes: Les neurologues des dix centres canadiens de l'AVC ont complété un questionnaire détaillé sur leurs patients âgés de 15 à 45 ans qui avaient été hospitalisés entre janvier 1993 et décembre 1997. Nous avons séparé les patients en trois groupes selon un algorithme diagnostique pas à pas incorporant les données cliniques, neuroradiologiques, neurovasculaires et biochimiques: (1) les patients dont la cause de l'AVC ischémique était établie; (2) ceux dont l'étiologie de l'AVC demeurait inexpliquée malgré une investigation adéquate; (3) ceux dont l'étiologie de l'AVC demeurait inexpliquée mais dont l'investigation était inadéquate à notre avis. Résultats: Chez 197 patients (56\%), la cause a été identifiée: une source d'embolie chez 14\%; une dissection artérielle extracrânienne chez 13\%; un infarctus lacunaire chez $8 \%$; l'athérosclérose chez $6 \%$. Un groupe hétérogène composé de $15 \%$ des patients comprenait des patients ayant subi une thrombose veineuse, des patients atteints de coagulopathies, de vasculite ou d'autres pathologies. Des 159 patients (44\%) n'ayant aucune cause apparente de leur AVC, nous avons considéré que seulement 81 patients (23\%), avaient été investigués adéquatement et 78 (21\%) ne l'avaient pas été. Conclusion: Environ un jeune patient sur cinq avait été mal investigué par un groupe de neurologues travaillant dans le domaine de l'AVC. Le problème majeur semble être une investigation limitée à la neuroimagerie (habituellement une tomographie cérébrale assistée par ordinateur), sans autre test comme une angiographie et une imagerie cardiaque.

Can. J. Neurol. Sci. 2000; 27: 120-124

Although stroke is a leading cause of death and disability in developed countries, ischemic stroke below the age of 50 years is relatively infrequent. In Canada in 1991, the incidence of cerebral infarction in persons below 54 years was about $13 / 100,000$, compared to $180 / 100,000$ in those aged $55-65 .{ }^{1}$ Consequently there are few studies with sufficiently large populations of young stroke patients on which to base adequate epidemiological data. The etiological spectrum is different in older patients where atherosclerosis is a major cause, while cardioembolism and arterial dissection are the main documented causes in the young. ${ }^{2-5}$ In up to one third of these young patients no cause was found, yet etiological attributions were often made, for which little or no evidence-based data were available.

In a preliminary national registry of young stroke patients undertaken by the Canadian Stroke Consortium (CSC), we were

From the Stroke Research Unit, Sunnybrook \& Women's College Health Sciences Centre, University of Toronto, Canada..

RECEIVEDNOVEMBER 9, 1999. ACCEPTED INFINALFORMFEBRUAR Y 15, 2000. Reprint requests to: Zurab Nadareishvili, Stroke Branch, NIH, NINDS, 36 Convent Drive, Bldg. 36, 4A03 Bethesda, Maryland, 20892-4128 U.S.A. 
surprised by the large number of patients who, on hospital discharge, had no established cause for their cerebral infarction. This study was undertaken to evaluate the reason for high incidence of diagnostic uncertainty in young patients with ischemic stroke.

\section{Methods}

Members of the CSC reviewed the records of all patients aged 15-45 years, using ICD-9 codes $(433,434,436,437)$ with a diagnosis of ischemic stroke, who were admitted between January 1993 and December 1997 to Canadian hospitals. After completing a special case record form, data were stored centrally by computer at the coordinating centre in Toronto. All identified arterial and venous strokes were included. We excluded transient ischemic attack (in view of the uncertainty of diagnosis), strokes secondary to surgical procedures, and patients with subarachnoid hemorrhage. In those who had more than one stroke during the study period, we included only the first episode.

Data included demographic factors, putative risk factors, clinical features, final hospital diagnosis, and all diagnostic and laboratory procedures such as computed cranial tomography (CCT) or magnetic resonance imaging (MRI), 24 hour monitoring of cardiac rhythm (Holter), hematological testing, transthoracic echocardiogram (TTE), transesophageal echocardiogram (TEE), carotid ultrasound, and all forms of cerebral angiography.

We studied the frequency and types of CCT, MRI, carotid doppler, TTE, and TEE, and determined how frequently specific hematological work-up were performed when these other tests proved negative.

We considered patients adequately investigated according to a step-wise, progressive, diagnostic algorithm if they had brain, neurovascular and cardiac imaging, as well as specific hematological testing including lupus anticoagulant (LA) and antiphospholipid antibodies (APLA), antithrombin III, protein C, protein $\mathrm{S}$, activated protein $\mathrm{C}$ resistance (factor $\mathrm{V}$ Leiden), hyperhomocystinemia, cholesterol and sickle cell factor. We

Table 1: Cause of stroke

\begin{tabular}{llll} 
Cause & $\begin{array}{l}\text { Total } \\
\mathbf{n = 3 5 6}\end{array}$ & $\begin{array}{l}\mathbf{1 5 - 3 0} \text { years } \\
\mathbf{n}=\mathbf{7 6}\end{array}$ & $\begin{array}{l}\mathbf{3 1 - 4 5} \text { years } \\
\mathbf{n}=\mathbf{2 8 0}\end{array}$ \\
Unknown & $159(44 \%)$ & $35(47 \%)$ & $124(43 \%)$ \\
Miscellaneous & $54(15 \%)$ & $18(23 \%)$ & $36(13 \%)$ \\
Cardioembolic & $51(14 \%)$ & $15(20 \%)$ & $36(13 \%)$ \\
$\begin{array}{l}\text { Dissection of } \\
\text { extracranial artery }\end{array}$ & $44(13 \%)$ & $7(9 \%)$ & $37(14 \%)$ \\
Small vessel disease & $27(8 \%)$ & $0(0 \%)$ & $27(10 \%)^{* *}$ \\
Large artery disease & $21(6 \%)$ & $1(1 \%)$ & $20(7 \%)^{*}$ \\
\hline
\end{tabular}

$* \mathrm{p}<0.01$ compared with 15-30 years old subgroup

** $\mathrm{p}<0.05$ compared with 15-30 years old subgroup
Table 2: Cardiac causes of stroke $(n=51)$

\begin{tabular}{lcc}
\hline Acquired $(\boldsymbol{n}=\mathbf{2 7})$ & $\mathbf{n}$ & \% \\
Ischemic heart disease & 17 & 33 \\
Rheumatic heart disease & 4 & 8 \\
Bacterial endocarditis & 3 & 6 \\
Atrial fibrillation & 2 & 4 \\
Atrial myxoma & 1 & 2 \\
Congenital (n=24) & & \\
Patent Foramen Ovale & 15 & 29 \\
Mitral valve prolapse & 3 & 6 \\
Valvular heart disease & 3 & 6 \\
Atrial septal defect & 3 & 6 \\
\hline
\end{tabular}

considered them inadequately investigated if the cause remained unexplained and only some of these investigations had been performed.

Risk factors were deemed present in patients already receiving treatment for hypertension, diabetes, hypercholesterolemia, ischemic heart disease and migraine and all drugs were documented including current use of contraceptive pills. Migrainous stroke was only diagnosed when the stroke occurred during or immediately after a migraine attack as defined by the International Headache Society (IHS) criteria. ${ }^{6}$ The diagnosis of arterial dissection was accepted only in the presence of angiographic imaging (catheter or MRI), in view of the limited value of Doppler. ${ }^{7}$

Strokes were classified into modified TOAST classification: ${ }^{8}$ 1. Large artery atherosclerosis; 2. Cardioembolic; 3 . Small vessel disease; 4. Dissection; 5. Miscellaneous (migraine, vasculitis, venous thrombosis, coagulopathies etc.); and 6. Unknown causes (Cryptogenic). In patients with more than one potential cause, we chose the most potent etiological factor and ascribed only one cause.

We divided the patients into two groups, 15-30 years of age, and 30-45 years of age, since the putative etiologies change during the three decades of age used in this study. Atherosclerosis, for example, is rare below age $30 .{ }^{9}$

Statistical evaluations were made by means of $t$ test to determine significant differences between means $(\mathrm{P}<0.05)$, and the $\chi^{2}$ test was used to determine significant differences between proportions. Data were stored on SPSS (version 7.5 for windows) software.

\section{RESULTS}

Records from a total of 356 patients in 10 centres were examined: $58 \%$ (207) were men, mean age $36 \pm 8$ years, and $42 \%$ (149) were women, mean age $35 \pm 7$ years.

Hypertension was present in $29 \%$, hypercholesterolemia in $10 \%$, cardiac disease in $14 \%$, diabetes in $12 \%$, migraine in $29 \%$ 
Table 3: Miscellaneous causes of stroke $(n=54)$

\begin{tabular}{lrc}
\hline Cause & $\mathbf{n}$ & $\%$ \\
Venous thrombosis & 13 & 24 \\
APLAand LA* & 8 & 15 \\
Migraine & 7 & 13 \\
Vasculitis & 6 & 11 \\
Substance abuse & 4 & 8 \\
Pregnancy or peri-partum & 4 & 8 \\
Moya-Moya disease & 2 & 4 \\
Meningitis/ vasculitis & 2 & 4 \\
Other** & 8 & $15^{*}$
\end{tabular}

*APLA indicates antiphospholipid antibody syndrome. LA indicates lupus anticoagulant.

**Single cases of Susac's microangiopathy, HIV, MELAS, homocystinemia, sickle cell crisis, subclavian steal, radiation arteritis and Epstein-Barr virus associated lymphoid granulomatosis were documented.

of women and in $12 \%$ of men. Eighteen percent of women were taking oral contraceptives and $12 \%$ were pregnant or within six weeks post-partum.

\section{Patients with established cause of stroke}

A cause for the patients stroke was found in 197 cases (56\%), the largest identified group being cardioembolic (14\%) [Table 1]. Arterial dissection was the second major cause (13\%) and in $25 \%$ of these cases, a recent history of cervical trauma was present, but since this is a retrospective study, the incidence of minor trauma may be underestimated. In patients $31-45$ years, dissection was the commonest identified cause of ischemic stroke.
Lacunes and carotid stenosis, were almost absent in the younger age group ( $<30$ years) (Table 1$)$.

Twenty-seven patients had acquired cardiac lesions and 24 had congenital cardiac lesions as the presumed cause of stroke (Table 2). In this group ischemic heart disease accounted for $33 \%(17 / 51)$ of the cases, followed by rheumatic heart disease $(8 \%)$, bacterial endocarditis $(6 \%)$, atrial fibrillation $(4 \%)$ and atrial myxoma (2\%). Patent foramen ovale (PFO) was the leading congenital cause of cardioembolic stroke $(29 \%, 15 / 51)$. In the absence of proof of a concomitant venous source, such as deep venous thrombosis (DVT), this cause must remain speculative, and we found no evidence of clinical and laboratory testing to confirm either a diagnosis of DVT or a concomitant coagulopathy. Atrial or ventricular septal defect and mitral valve prolapse were other congenital cardiac causes of stroke, each representing $6 \%(3 / 51)$.

The miscellaneous group (Table 3) consisted of cerebral venous thrombosis as the most common cause (24\%), followed by APLA syndrome (15\%), and $13 \%$ with an ischemic cerebral lesion accompanied by a migraine attack. One patient, presenting initially with stroke but both negative CT and cerebral angiography, was readmitted three months later with another "transient ischemic attack (TIA)" when MR scanning immediately identified the typical plaques of multiple sclerosis.

\section{Patients with unknown cause}

Among 159 patients (44\%) where no cause for their stroke was found, $81(23 \%)$ were adequately investigated according to our predefined criteria, but $78(21 \%)$ were inadequately investigated. There was no significant difference in the frequency when carotid duplex was used, or in cardiac imaging studies (Table 4), but inadequately investigated patients had significantly less angiography $(\mathrm{p}<0.001)$, TEE and TTE than patients with established causes of stroke. There was no significant difference in the frequency of investigations between patients with established causes of stroke and those who remained unexplained even after adequate investigation, so there still remains a group of unexplained cause in spite of complete neurological, vascular and hematological investigations (81/159 $=55 \%$ of the cryptogenic group) (Table 4 ).

Table 4: Frequency of investigations $(n=356)$

\begin{tabular}{|c|c|c|c|c|}
\hline Investigations & $\begin{array}{l}\text { Established } \\
\qquad n=197\end{array}$ & $\begin{array}{c}\text { Unknown } \\
\text { (“Cryptogenic") } \\
n=159\end{array}$ & $\begin{array}{c}\text { Unknown with } \\
\text { completely investigated } \\
n=81\end{array}$ & $\begin{array}{c}\text { Unknown with } \\
\text { inadequately investigated } \\
\mathrm{n}=78\end{array}$ \\
\hline Angiogram & $138(70 \%)^{*}$ & $77(49 \%)$ & $57(70 \%)$ & $20(25 \%)$ \\
\hline Duplex & $75(38 \%)$ & $70(44 \%)$ & $46(57 \%)$ & $24(31 \%)$ \\
\hline TTE & $125(64 \%)^{* *}$ & $108(68 \%)$ & $81(100 \%)$ & $27(35 \%)$ \\
\hline TEE & $54(27 \%)^{* *}$ & $36(22 \%)$ & $31(38 \%)$ & $5(6 \%)$ \\
\hline Hematology & $177(90 \%)$ & $106(67 \%)$ & $80(99 \%)$ & $26(34 \%)$ \\
\hline
\end{tabular}

* $\mathrm{p}<0.001$ compared with unknown

$* * \mathrm{p}<0.001$ compared with inadequate investigation 


\section{Discussion}

In published studies of young stroke patients, the etiology remains completely unexplained in $23-50 \%$ of the cases. ${ }^{2-5}$ Some of these etiological discrepancies between published series of ischemic stroke in the young may represent regional differences, such as the relative high occurrence of stroke induced by drug abuse in large cities in the $\mathrm{USA}^{10}$ or by alcohol in Finland. ${ }^{2}$ However, we believe a major reason so many remain unexplained is either the lack of adequate neurovascular investigation or the incorrect perception of the weighting of risk factors. For instance, in a pooling of data in three German data banks, of 1564 patients with stroke or TIA, 17\% were attributed to cardiogenic causes. Patients investigated by TEE compared to those without this investigation had much higher rates of cardiac thrombus ( $11 \%$ vs $2.4 \%$ ), mitral valve prolapse (22\% vs $0.6 \%$ ) and PFO ( $7.4 \%$ vs $0 \%)$, yet the authors concluded that this investigation did not appreciably aid in determining the cause of the stroke. ${ }^{11}$

Cardiac lesions previously considered benign, such as asymptomatic chronic atrial fibrillation, are now recognized as powerful sources of cardioembolic stroke, with an annual frequency of about $4 \%$ of ischemic strokes. ${ }^{12}$ Although one in five otherwise normal people have detectable PFO this is increasingly recognized as an established cause of paradoxical embolism. ${ }^{13}$ Although the presence of PFO alone (or associated abnormalities such as atrial septal aneurysm) does not justify a causal relationship, recent data indicate that the majority of patients with stroke have evidence of deep vein thrombosis (evident on imaging but not necessarily clinically). ${ }^{14}$ Therefore, when a PFO is considered as a possible cause of cerebral embolism, besides a clinical search for DVT venography, radionucleide or ultrasound imaging are also mandatory, ${ }^{15}$ and failing that, hematological testing for coagulopathy defects should be performed.

Arterial dissection, previously believed a rare phenomenon, has been increasingly recognized due to safer neurovascular imaging, both by catheter or MR angiography, and in one series was the most frequent determined etiology. ${ }^{2}$ Though sometimes visualized by ultrasound methods, the specificity of the Doppler technique alone is often inadequate for a reliable diagnosis. ${ }^{7}$

Abnormalities of blood coagulation were rare in this study, APLA elevations were present in only $4 \%$, and homocystinemia in $1 \%$ of patients, in keeping with previous published figures. ${ }^{16}$ Coagulopathy studies can be deferred until after the initial diagnostic imaging has proven negative.

In older stroke populations ( $>45$ years) the major cause of ischemic stroke is atherosclerosis of large arteries, lacunar infarction due to small artery disease, and cardioembolic stroke predominantly due to atrial fibrillation. Together, these comprise $40-50 \%$ of all cases. ${ }^{17}$ In young patients there should be a different approach to prevention of recurrence, since the common causes are congenital cardiac lesions and extracranial arterial dissection, with less frequent involvement of small and large cerebral or extracranial arterial disease. In the Baltimore-Washington study of traditional risk factors for ischemic stroke, in 296 young patients compared with controls, an increased prevalence of hypertension, diabetes and cigarette smoking were found significant, but unfortunately no data regarding stroke types are available, so the relevance of the relationship remains uncertain. ${ }^{4}$
The routine use of aspirin as the ubiquitous stroke prophylaxis is rarely indicated in young patients with ischemic stroke when there is no evident cause after complete investigation. In young patients with ischemic stroke, when all investigations have been proven negative, there is a tendency to prescribe aspirin nonspecifically. This is not evidence-based and raises the question of how long the medication should be administered? Aspirin is not devoid of adverse effects and should not be prescribed without pharmacological justification. No patient should be abandoned diagnostically until the full range of cerebral, neurovascular and cardiac imaging, in conjunction with hematological testing is utilized. We believe that if these steps had been undertaken in our patients, the cause of stroke may have been identified in up to $21 \%$ more cases, leading to improved treatment and prevention of further episodes.

\section{APPENDIX}

\section{Canadian Stroke Consortium Collaborators}

Neville Bayer, MD, St. Michael's Hospital, Toronto, Ontario

Alastair Buchan, MD, University of Calgary, Alberta

Robert Coté, MD, Montréal General Hospital, Montréal, Québec

Vladimir Hachinski, MD, Arturo Tamayo, MD, University of Western Ontario, London, Ontario

Marek Gawel, MD, Scarborough Centenary Hospital, Toronto, Ontario John Maher, MD, Neurophysiology and Epilepsy Centre, Winnipeg, Manitoba

Beverly Bowyer RN, Sunnybrook \& Women's College Health Sciences Centre, Toronto, Ontario

Stephen Phillips, MD, Queen Elizabeth II Health Sciences Center, Halifax, Nova Scotia

Frank Silver, MD, The Toronto Hospital, Western Division, Toronto, Ontario

Michael Winger, MD, Windsor Health Centre, Windsor, Ontario

\section{REFERENCES}

1. Mayo NE, Neville D, Kirkland S, et al. Hospitalization and casefatality rates for stroke in Canada from 1982 through 1991. The Canadian Collaborative Study Group of Stroke Hospitalizations. Stroke 1996;27:1215-1220.

2. Bogousslavsky J, Pierre P. Ischemic stroke in patients under age 45 . Neurol Clin 1992;10:113-124.

3. Adams Jr HP, Kappelle LJ, Biller J, et al. Ischemic stroke in young adults. Experience in 329 patients enrolled in the Iowa Registry of Stroke in Young adults. Arch Neurol 1995;52:491-495.

4. Rohr J, Kittner S, Feeser B, et al. Traditional risk factors and ischemic stroke in young adults: the Baltimore-Washington Cooperative Young Stroke Study. Arch Neurol 1996;53:603-607.

5 Kittner SJ, Stern BJ, Wozniak M, et al.Cerebral infarction in young adults. The Baltimore-Washington Cooperative Young Stroke Study. Neurology. 1998; 50:890-894.

6. Headache Classification Committee of the International Headache Society. Classification and diagnostic criteria for headache disorders, cranial neuralgias, and facial pain. Cephalalgia 1988; $8: 27$.

7. Bartels E, Flugel KA. Evaluation of extracranial vertebral artery dissection with duplex color- flow imaging. Stroke 1996;27:290295.

8. Adams Jr HP, Bendixen BH, Kappelle LJ, et al. Classification of subtype of acute ischemic stroke. Definitions for use in a multicenter clinical trial. Stroke 1993;24:35-41.

9. Bogousslavsky J, Regli F. Ischemic stroke in adults younger than 30 years of age. Arch Neurol 1986; 43:793-796.

10. Sloan MA, Kittner SJ, Feeser BR, et al. Illicit drug-associated ischemic stroke in the Baltimore-Washington Young Stroke Study. Neurology 1998;50:1688-1693. 
THE CANADIAN JOURNAL OF NEUROLOGICAL SCIENCES

11. Hornig CR, Brainin M, Mast H. Cardioembolic stroke: results from three current stroke data banks. Neuroepidemiol 1994;318:318323.

12. Ezekowitz MD, Bridgers SL, James KE, et al. Warfarin in the prevention of stroke associated with nonrheumatic atrial fibrillation. N Engl J Med 1992;327:1406-1412.

13. Hata JS, Ayres RW, Biller J, et al. Impact of transesophageal echocardiography on the anticoagulation management of patients admitted with focal cerebral ischemia. Am J Cardiol 1993;72:707-710.

14. Lethen H, Flachskamp FA, Schneider R, et al. Frequency of deep vein thrombosis in patients with patent foramen ovale and ischemic stroke or transient ischemic attack. Am J Cardiol 1997; 80:1066-1069.

15. Perrier A, Desmarais S, Miron MJ, et al. Non-invasive diagnosis of venous thromboembolism in outpatients. Lancet 1999;353: 190195.

16. Ferro D, Quintarelli C, Rasura M, Antonini G, Violi F. Lupus anticoagulant and the fibrinolytic system in young patients with stroke. Stroke 1993;24:368-370.

17. Mohr JP, Sacco RL. Classification of ischemic strokes. In: Barnet HJM, Mohr JP, Stein BM, Yatsu FM, eds. Stroke: Pathophysiology, Diagnosis and Management. 2nd ed. New York: NY: Churchill Livingstone; 1992:271-283. 